\title{
What the Weatherman Said Enrichment, CTT and the Dialogical Approach to Moderate Contextualism.
}

\author{
Shahid Rahman \\ Université de Lille \\ Département de philosophie \\ CNRS, UMR 8163 -STL \\ Lille, France
}

\begin{abstract}
The main aim of the present paper is to show that the recently developed dialogical approach to Martin-Löf's Constructive Type Theory (CTT), called Immanent Reasoning, provides, the means for distinguishing François Recanati's process of free enrichment and saturation, meets his own objections against perspectives based on unarticulated constituents, and opens a new venue to pragmatic modulation, where the speaker-receiver interaction is integrated into the notion of enrichment. In such a setting enrichment operates on proof-objects that make fully articulated event-propositions true. The point is that by distinguishing what makes a proposition true from the proposition made true offers a simple and clean way to avoid conflating the contextual elements that enrich a proposition with the proposition itself. Such a framework abounds in means for expressing reference structures such as anaphora, including time and/or location reference. Furthermore, the notion of dependent types of CTT (absent in Montague-style semantics) and the associated formation rules allow a straightforward analysis of composition of meaning at work in Recanati's cases concerning occasion meaning as determined by context.

The brand of dialogical contextualism, grounded on the play-level (where propositional content is not necessarily truthconditional), advocated herewith is not a form of propositional syncretism. The framework offers a straightforward response to the failure of third excluded in some instances of faultless disagreement without giving up the notion of propositional content. More generally, this suggests an alternative way to tackle the interface pragmatics semantics underlying the notion of pragmatic modulation by integrating into the interface the dialogical game of asking and giving reasons.
\end{abstract}

\section{Introduction}

In his work Perspectival Thought François Recanati (2007a), who is one of the most highly estimated representatives of contemporary Contextualism, distinguishes three semantic levels:

(i) the "Fregean" context-independent meaning of a sentence (associated with the unrelativized proposition expressed by the sentence),

(ii) the lekton, a term that Recanati borrows from Stoic Logic, ${ }^{1}$ the content of a sentence with respect to context, which falls short before constituting a proposition since some determinants of truth-conditions (i.e. circumstances of evaluation) are left unarticulated (do not correspond to any element in the sentence) and are provided by the situation,

(iii) the Austinian proposition that comes out by associating the lekton with a situation serving as circumstance of evaluation.

\footnotetext{
${ }^{1}$ In a fascinating paper that displays skills proper of a detective, Gabriel/Hülser/Schlotter (2009) suggest that there are strong indications that Frege's notion of Gedanke (thought) has been directly inspired if not borrowed from the Stoic notion of lekton.
} 
Recanati's point is to introduce the intermediate level (ii) for sentences such as it is raining where the contextual circumstance of utterance (place or time) is tacit in the lekton, despite the fact that the utterance of the sentence, e.g. It is raining, is false in some circumstance and false in others - cf. Recanati (2007a, pp. 50-51) ${ }^{2}$. In contrast, to a sentence where a location and/or time indexical makes of the circumstance of evaluation an articulated part of the lekton, such as it is raining here; it is raining now.

More generally, Contextualists, argue that the influence of context, or pragmatic factors, is necessary in the determination of semantic content - understood as truth-conditional propositional content. According to this view the compositional elements of a sentence rarely, if ever, deliver a determinate proposition. It is the utterance or speech act that is the proper unit of linguistic analysis according to contextualists, for it is only at the point of use that propositional content is expressed. ${ }^{3}$

Recanati uses the example of the sentence I am French to distinguish formal meaning, what is said and implicatures. The formal meaning of the first level of meaning, or the literal sentence meaning in this example is the context-independent idea that the speaker of this sentence is French. This literal sentence meaning does not vary from context to context; it always expresses the notion that whoever utters the sentence is French. Formal meaning is opposed to the context-dependent proposition, that gets expressed by the lekton within particular contexts of use. For example, if Recanati utters the sentence it expresses the proposition that he is French, but if I were to say it, it would be a different proposition, namely, that I am French. Finally, there is the distinction between what is said -the lekton- and the implicature. Recanati supposes a context in which he is asked whether or not he is a good cook. He responds: "I am French". Clearly in this case, his utterance expresses not only that he is from France, but it also implicates that he is indeed a good cook. Now, implicatures assume that the lekton has been already grasped, this is where, according to Contextualists, the Gricean approach gets it wrong: the latter perspective goes from the context independent proposition to the implicature.

The point of Recanati's approach is that propositional content cannot be grasped without a pragmatic process of fleshing out the meaning of the sentence so as to make it propositional" Recanati (2004, p. 25). In order to show this, he describes three further pragmatic processes: free enrichment, loosening, and transfer. Each of which is defined by the fact that they are top-down, or optional context-driven processes that are involved in the primary interpretation of linguistic utterances and yield truth-conditional content.

Free-enrichment essentially consists in making the interpretation of some expression in the sentence contextually more specific" - Recanati (2004, p. 24). Take the example Mary took out her key and opened the door door. The idea here is that (under normal circumstanced) the receiver of the utterance of the sentence would assume that the expression means that Mary opened the door with her key. Yet, there is no constituent in the sentence itself that articulates this fact. On strict literal reading the sentences expresses a conjunction punkt.

\footnotetext{
${ }^{2}$ As we will discuss in the next section one should not think that at the intermediate level, the relation between the lekton and the circumstance of evaluation as the relation between some minimal unity of meaning (allegedly; the lekton) and that circumstance, but rather as a the lekton affected by that cirucmstance. Recanati (2017) contests the minimalist interpretatoin of the intermediate level proposed by by Kölbel (2017).

${ }^{3}$ Cf. Grant (2019), who develops a helpful general discussion on Recanati’s Contextualism. .
} 
Loosening, the converse of enrichment, relaxes the conditions of application as opposed to tightening them. Take the sentence The ATM swallowed my credit card",By loosening the criteria of use for the term "swallowing" one can easily understand the truth-conditions for this sentence. Also, there is, again, nothing in the sentence itself that explicitly permits this loosening to occur; it is top-down.

The third primary pragmatic process, is known as semantic transfer. An example of transfer is found in the utterance The ham sandwich left without paying - Recanati (2004, p. 26). It seems that the meaning of Ham sandwich orderer" is transferred on to the phrase "ham sandwich" though there is no linguistic mandate to do so. ${ }^{4}$

Thus, despite the fact that the lekton of the intermediate level, a relativized proposition (true at some situations and false at others) or a quasi-proposition, falls short of determining its absolute truth-conditions a pragmatic modulation process of free enrichment can, but must not be bring to the fore a situation of evaluation relevant for determining its truth-value. This view contrasts with other contextualist approaches that assume that the content of sentences like it is raining require a mandatory tacit variable for location (for instance, city, country, etc.). Such approaches, launched by John Perry's (1986) famous paper "Thought without Representation”, conceive in fact the content of It is raining as a propositional function with a variable for location that needs to be saturated, despite the fact that they acknowledge that syntactically nothing is missing in sentences such as It is raining:

\section{[...]. Thus though:}

(7) It is raining

is missing no syntactically mandatory sentential constituent, nonetheless it is semantically incomplete. The semantic incompleteness is manifest to us a felt inability to evaluate the truth value of an utterance of (7) in the absence of a contextually provided location (or range of locations). This felt need for a contextually provided location has its source, I claim, in our tacit cognition of the syntactically argument place of the verb 'to rain'. Taylor (2001, p. 53).

For short, saturation is a pragmatic process of contextual value-assignment that is triggered (and made obligatory) by something in the sentence itself, namely the linguistic expression [such as an indexical] to which a value is contextually assigned" - Recanati (2010, p. 4). Recanati's main objections to the saturation approach as a general approach to contextuality in a nutshell are three. The third main objection carries most of the weight of Recanati's plaidoyer for contextualism:

- The first main objection can perhaps be declined in two parts. The first part recalls John L. Austin's warning not to conflate content and circumstance of evaluation ${ }^{5}$. The second part joins Michael Dummett's criticism

\footnotetext{
${ }^{4}$ Notice that the kind of moderate Contextualism professed by Recanati does not commit him to the claim that every process of completing incomplete proposition must fall in one of the three categories. There are cases that are not result of enrichment, such as completing Everyone loves Sally to Every one loves Sally and his mother; However identifying those cases contribute to the task of identifying the class of linguistic phenomena captured by modulation - Elbourne (2008), Recanati (2010, pp. 10-12).

${ }^{5}$ Truth-evaluation (or semantic evaluation more generally) requires not merely a content to evaluate, but also a 'circumstance' against which to evaluate that content. As Austin once put it, 'it takes two to make a truth'. The circumstance of evaluation is not an aspect of the content to be evaluated, but an entity with respect to which that content is evaluated. Still, according to the theory of situations to be introduced in this chapter, the circumstance of
} 
of those approaches that take tenses as constitutive arguments of the content of adjectives. As pointed out by Recanati (2004, pp. 118-19) while commenting Dummett's observation, if we choose the relational view on tenses as mandatory constituents of adjectives, adjectives such as warm and yellow can no longer be considered as expressing properties but as a relation between the object having the property and the time it entertains that property. Such a relational view departures significantly from our habitual way of learning the use of an adjective. Dummett's point is that to [...] understand 'warm' or 'will be warm' we apply to our prior understanding of what is meant by saying that something is warm our general comprehension of what is to speak of how things were or will be in another time. Dummett (1997).

- The second main objection parallels the saturation approach to the incorporation of unarticulated constituents with the traditional argument analysis of adverbs. The traditional analysis of adverbs as values of propositional functions overlooks the fact that is not possible to specify in general the exact number and kind of adverbial arguments that a predicate might hold. ${ }^{6}$ In a similar way as adverbs and modifiers can be multiplied in several dimensions, the content of the verb to rain in It is raining can always be further specified in different degrees (even if we only consider the locative dimension) - e.g. (i) It is raining in Lille (given some evidence of a rain-event taking place in that location), or (ii) It is raining somewhere on earth (given some evidence of a rain-event taking place at least one location on earth), (iii) It is raining over earth (given some evidence of rain-events taking place at most locations on earth): optionality is the hallmark of enrichment. However, this does not preclude acknowledging that some verbs such as arrive do require a slot for a location argument. Recanati's (2007b, pp. 143-145) point is that while John has arrived does engages saturation, It is raining patterns with John has danced in the sense that their logical form of both do not include a slot for location. This contrasts with the followers of the saturation approach, who acknowledge that to dance does not require a variable for location but refuse to pattern to rain wit too dance. Thus, according to the saturation perspective a sentence either expresses a complete proposition, such as John has danced, or it does not, such as John has arrived: 7 there is no intermediate case. Recanati's all point is that there is such a intermediate level and this is why enrichment must be added to the process that account for communicative success. This takes us to his third objection:

- The third main objection constitutes the core of Recanati's moderate contextualism. According to the saturation view; whereas the answer Have not a clue! is an acceptable answer to the question Where did John dance? (given the assertion John has danced), the same answer is patently unacceptable if the question is Where did John arrive? (given the assertion John has arrived). ${ }^{8}$ Similarly, under this perspective the speaker of It is raining, cannot avoid answering Where? Now, if the saturation perspective is right there is no possible context where an expression with a tacit constituent (e.g, a location indication) yields a truth-evaluable statement unless that constituent has been provided. ${ }^{9}$ However, Recanati’s (2002, p. 316) invites us to

evaluation is an aspect of content in a broader sense of 'content'. And that aspect of content is irreducibly contextual. Recanati (2004, p. 115).

${ }^{6}$ The view I have sketched escapes the difficulties that beset the traditional 'argument analysis' of adverbs. The problem with treating what adverbs contribute as further arguments of the relation expressed by the verb is that this assumes something patently untrue [...]. As adverbs and modifiers can always be multiplied, and new dimensions of modification can always emerge, the standard argument analysis is clearly hopeless. But the view I have sketched meets both objections: the number and identity of adverbial arguments do not have to be specified in advance, and whatever information they convey does not have to be regarded as implicit when they are not provided (whether linguistically or contextually). Recanati (2002, footnote 18, pp. 322-323).

${ }^{7}$ Notice that Recanati's analysis of John has arrived also applies to the examples brought forward by Tomohiro Sakai (2014). such as I like very much. Sakai (2014) joins Stanley (2005) in casting doubts about the (grammatical) force of Recanati's arguments for enrichment. Perhaps, the reconstruction of enrichment within a framework of type-theoretical grammar developed in the next sections will help to dissipate some doubts.

${ }^{8}$ Kent Bach $(2004,2005,2006)$, who labels himself as a radical minimalist, shares with Recanati the view that there are sentences that are semantically incomplete, such as John arrived, though he calls them propositional radicals rather than lekta. However, different to Recanati's contextualism Bach (2006) strongly contest the view that semantic incomplete sentence can be completed by context. Completion is a semantic and not a pragmatic process. Expansion, is a pragmatic process but on Bach's view it applies to already semantic complete sentences.

${ }^{9}$ I conclude that what characterizes genuine unarticulated constituents is the fact that their contextual provision is not mandatory - it is not required in virtue of a linguistic convention governing the use of a par ticular construction (or class of constructions). In context, it may be that the unarticulated constituent is 'required'; but then it is required in 
consider the following case where the fact that a evaluation circumstance is tacit - namely, location - neither prevents from distinguishing a fully articulated content nor does it frustrate the constitution of a complete proposition - the latter is the result of the free pragmatic modulation process of enrichment:

I can imagine a situation in which rain has become extremely rare and important, and rain detectors have been disposed all over the territory (whatever the territory-possibly the whole Earth). In the imagined scenario, each detector triggers an alarm bell in the Monitoring Room when it detects rain. There is a single bell; the location of the triggering detector is indicated by a light on a board in the Monitoring Room. After weeks of total drought, the bell eventually rings in the Monitoring Room. Hearing it, the weatherman on duty in the adjacent room shouts: 'It's raining!' His utterance is true, iff it is raining (at the time of utterance) in some place or other. Recanati (2002, p. 317).

Indeed, in this example the bare ringing of the bell makes the answer I have not a clue! a plausible response to the question Where? directed at the weatherman's assertion It is raining. The weatherman conveyed an information that can be used to draw some further inferences or decisions - such as reducing the restrictions on the consumption of water.

Another important criticism of Recanati, relevant to our paper, concerns what Jason Stanley (2005) calls propositional Syncretism as represented by Scott Soames (2002, 2005), Emma Borg (2004), and Herman Cappelen \& Ernie Lepore (2005). In fact Recanati’s rejection of propositional Syncretism constitutes an important motivation of promoting lekta, or quasi-propositions, as the inputs of enrichment processes. Lekta are neither propositional functions waiting to be saturated nor minimal propositions acting as common denominators of whatever assertions might result from pragmatic modulation processes:

- According to propositional Syncretism, also called (propostional) Minimalism, semantic contents of sentences in contexts are always propositions, but not usually the propositions the users of those sentences intend primarily to assert. Rather, semantic contents are generally "minimal propositions" (as in the work of Cappelen and Lepore (2005)). Stanley (2005), based on Recanati’s (2004, pp. 51-67) objections, provides the following example that stresses some of the main points of Recanati against propositional Syncretism. If we assume that the minimal content expressed by Every bottle is in the fridge, in any context, is the false proposition that every bottle in the entire universe is in the fridge, adherents of propositional Syncretism must endorse the view that this content, that in fact it is never asserted or conveyed by an utterance is the input of the process that yields the content of the uttered sentence. Similarly the speaker who assertively utters The ham sandwich left without paying, does not assert the minimal proposition that the sandwich left without paying! - Recanati (2004, pp. 60-61). Thus, in this case, contrary to the principles of Propositional Syncretism, the minimal proposition is not part of the content of what is asserted. In fact the kind of minimalism advocated by propositional Syncretism only works when the asserted content is richer than the alleged semantic content (Recanati (2004, p. 60)). This is related to the availability constraint of genuine content. The point is that the pragmatically enriched proposition is the only one that the interlocutors are consciously aware of within a speakerreceiver interaction. In other words, the non-enriched proposition, such as the one claimed by propositional Minimalists, is not available to the interlocutors involving sentences such as Every student passed the logic exam.

virtue of features of the context, not in virtue of linguistic properties of the expression-type. A constituent is mandatory in the relevant sense only if in every context such a constituent has to be provided (precisely because the need for completion is not a contextual matter, but a context-independent property of the expression-type). This, then, is the criterion we must use when testing for (genuine) unarticulatedness: Can we imagine a context in which the same words are used normally, and a truth-evaluable statement is made, yet no such constituent is provided? If we can imagine such a context, then the relevant constituent is indeed unarticulated (in the strong sense); if we cannot, it is articulated, at some level of linguistic analysis. Recanati (2002, 316). 
Now, Recanati (2010, p. 120) points out that one way to implement enrichment, the modulation process we will focus on, is to build an account that takes the location-less reading as basic and the location--specific reading as pragmatically derived, while appealing to the notion of variadic shift to account for the pragmatic derivation of the latter from the former. Variadic shifts are the result of what Recanati (2002, pp. 318-323) calls a variadic function, that increases or decreases the arity of the relation it applies to. A useful way to grasp the notion of variadic function is to contrast those variadic functions that implement enrichment by expansion, to W. v. O. Quine's (1960) recessive de-relativization operator DER. ${ }^{10}$ Indeed whereas Quine's recessive-DER suppresses an argument of an n-adic relation (e.g. DER transforms the dyadic relation John-kisses-Mary into the monadic Mary-is-kissed(by John)), the variadic function that implements enrichment is an expansive function that adds an argument. Now, given that according to Recanati's approach the lekton of It is raining is fully articulated, and it thus has the logical form of a cero-adic predicate, the enrichment process as implemented by an expansive variadic function, transforms the 0 -adic predicate into monadic one, namely one where there is an argument for location (leaving the temporal dimension aside). More precisely: The variadic functions that increase the valence of the input relation through the addition of a circumstance to the set of its argument-roles can be represented by means of an operator (or rather, a family of operators) Circ. When applied to an $n$-place predicate $P$, Circ produces an $n+1$ place predicate (Circ P). There will be as many Circoperators as there are argument-roles which can be added to the set of argumentroles of the input relation. There will be a temporal Circ-operator, a locational Circoperator, etc., depending on the nature of the extra argument-role. Which Circ-operator is at issue will be indicated by means of a subscript. For example, the operator_Circlocation 'contributed by locative modifiers (such as the prepositional phrase _in Paris") will map the $\left[0\right.$-adic rain ${ }^{11}$ into the monadic predicate rain_in relation by adding a Location argument-role. Recanati (2002, p. 321).

Thus, enriching It is raining, into It is raining (in Paris) is carried out by the variadic function

- $\quad$ CirClocation: Paris(It is raining) $=$ It is raining_in (Paris)

Thus the result of an expansive variadic function such as Cirlocation or simply Loc, takes us from the set of those events $e$ that are raining events
$\lambda e[\operatorname{RAINING}(e)]$
given $e \in$ Events

to the set of those events that are raining-events and have an assigned location

$$
\lambda(l) \lambda(e)[\operatorname{RAINING}(e) \& \operatorname{LOCATION}(l, e)] \quad \text { given } l \in \text { Locations, } e \in \text { Events }
$$

However, this is not yet enrichment. According to Recanati (2010), who follows here McConnell-Ginet (1982) account of adverbials, enrichment is implemented when the expansive variadic function accomplishes two roles at the same time: namely (i) adding a dimension, by integrating an argument role (in our case a locative dimension); (ii) filling the argument with a specific value (say, Lille). Enriching raining with a locative dimension, when implemented by an expansive variadic function yields

\footnotetext{
${ }^{10}$ In fact, also Quine's DER-operator can do both increase or decrease the arity of a relation.

11 The original text maps Eat relation to the Eat-in relation.
} 
$\lambda(e)[\operatorname{RAINING}(e) \& \operatorname{LOCATION}($ Lille, $e)]$ given Lille $\in$ Locations, $e \in$ Events.

Or in the more usual notation of Montague-Grammars:

$\lambda(e)[\operatorname{RAINING}(e) \& \operatorname{LOCATION}(l, e)($ Lille $)] \quad$ given Lille $\in$ Locations, $e \in$ Events.

The enriched predicate can be now deployed to build a Davidsonian event-proposition of the form

$\exists(e)[\operatorname{RAINING}(e)$ \& LOCATION $($ Lille, e $)]$

Thus, in this version, the result of enrichment is represented as the contextual provision of a conjunct. This conjunction is a dyadic relation between events and locations. If we make time explicit we have the following conjunction:

$\exists(e) \exists(t)[\operatorname{RAINING}(e) \& \operatorname{PRESENT}(t) \& \operatorname{TIME}(t, e) \& \operatorname{LOCATION}(\text { Lille }, e)]^{12}$ given Lille $\in$ Locations, $e \in$ Events, $t: \in$ Time-Scale

Now, while representing LOCATION as a relation linking events and places seems to be in principle plausible, a TIME relation defined over a quantification domain of time moments is less appealing - even if the quantification is of the substitutional brand - as the one favoured by Recanati (2007a, pp. 58-59). In fact, as we will discuss below it is quite straightforward to define timing functions that take events as input and yield names of time moments instead. In any case, we do not need to assume that all contextual provisions have the same structure.

Be that as it may, there are four main criticisms to Recanati's moderate pragmatism that are relevant for our present paper. The first is in principle in sympathy to Recanati's proposal. The other two, include different readings of the weatherman example congenial with saturation rather than with enrichment. The latter three criticisms can be understood as receiving support from Stanley's (2005) binding-argument. According to Stanley's viewpoint, there cannot be binding without a variable ready to be bound, hence that an argument-role can be bounded shows that the contextually provided constituent filling that role is articulated by a free variable occurring in the logical form, for short the logical form is that of a (tacit) propositional function. Furthermore, saturation, so the argument goes, not only explains how to unify unarticulated constituents with propositional content, it explains also in recursive way that preserves syntactic and semantic compositionality.

- Max Kölbel (2017, pp. 208-210), who shares important views with the ones of Recanati(s moderate contextualism, points out that if the notion of lekton is equated with the notion of what is said - lekton is the Greek word for what is said after all, then it looks as if some tension might arise between the concept of lekton deployed in Recanati's books Literal Meaning and Perspectival Thought. According to this worry, one hand Recanati's (2007a, 2007b) lekton of the intermediate level is fully articulated in the sense that nothing is in the lekton that does not correspond to some element in the sentence; on the other, in his earlier work seems to argue that what is said tacitly involves unarticulated constituents provided by free enrichment. In his response to Max Kölbel (2017) Recanati (2017, pp. 219-220) indicates that

\footnotetext{
${ }^{12}$ Cf. Recanati (2007, p. 133).
} 
enrichment should not be conceived as a process of adding contextual constituents to a some underlying tacitly assumed Austinian proposition from which these constitutents have been supressed, but as topdown optional aggregative specification process of adding adjunctive time or locative adverbials to a fully articulated content, the lekton, that; does not contain the contextual parameters required for its evaluation. In other words, we do not have first a fully complete Austinian proposition from which one extracts the lekton, but enrichment can produce one or other Austinian proposition. ${ }^{13}$

- The second criticism, which follows from Perry's (1986) analysis of meteorological sentences, insists that $I t$ is raining does include a tacit slot for a specific location, and this also applies to the weatherman example. The specific location tacit in the weatherman's assertion is On Earth - cf. Luisa Marti (2006, pp. 153-154). However, as pointed by Recanati (2007b, pp. 137-138) this proposal owes a linguisticdriven explanation on why the specific location Earth should be understood in a broad sense (in at least one location on Eearth) rather than in a narrow sense (Over Earth, i.e; in most of the locations on Earth). Moreover, even if it is conceded that the location specific to weatherman is Earth in the broad sense this shows that rain patterns with dance not with arrive. Indeed, whereas John has arrived cannot be understood as John arrived somewhere on Earth (if we consider the answer I do not have a clue! to the question Where? to be inappropriate), both John has danced somewhere on Earth and It is raining somewhere on Earth are compatible with the answer I do not have a clue! to the question Where? - cf. Recanati (2007b, pp. 144-145). ${ }^{14}$ This might suggest that there is a tacit variable, for a specific location but that sometimes it should be understood in the broad sense and sometimes in the narrow sense. This form of response is close to the following form of criticism that appeals to optional variables.

- According to an alternative reading, weatherman meteorological predicates like rain carry an argument slot for location. However, so the alternative proposal goes, the argument slot needs not to be filled with a specific location (in the narrow sense); it may be bound by a covert existential quantifier. Moreover, existential closure should be assumed by default. Thus, It is raining, can be understood as both, It is raining (in Lille) or if specific location is not available - as in the weatherman example - then it should be understood as the closed sentence It is raining (somewhere on Earth). This position, a follow-up from Partee's (1989) work on indexicals, faces the problem of providing a lexical driven explanation on how to choose between a narrow and broad scope of the existential quantifier in relation to negation when a negative variant of the weatherman is at stake - whereby instead of detecting rain the device detects absence of rain. Indeed, if existential closure is the default binding procedure, why is it that in the case of a negative variant the weatherman's assertion It is not raining should be read as It is not the case that at some location there is rain, rather than There is a location, where there is no rain ? In fact, according to this approach It is not raining should be read as It is not raining on Earth, but this should be read as There is no raining spot - cf. Recanati (2010, pp. 104).

- Perhaps the toughest general objection against Recanati's takes on contextualism is the complain that the notion of context-dependence makes it difficult if not impossible to deal with systematic, recursive and

\footnotetext{
${ }^{13}$ I deny that there is any such tension. I agree with Kölbel that the lekton should be equated to what is said for all the reasons he gives. Indeed their being identical is one of the reasons why I use that term 'lekton' which means 'what is said' (and additionally conveys the suggestion of semantic incompleteness, due to the use of the term by Stoic logicians in connection with tensed propositions). [...]. Is not free enrichment, the paradigmatic modulation process, the provision of unarticulated constituents? No it is not. In free enrichment some aspect of meaning is contributed in a top down manner by the context. This is often interpreted as the provision of 'unarticulated constituents', but that is not my interpretation. Free enrichment typically corresponds to a process of specifization, through which we make the contextual meaning of a lexical item more specific than its literal (conventional) meaning. Is this a matter of providing unarticulated constituents? No. The contextual meaning, resulting from free enrichment, is not unarticulated, because it corresponds to something in the sentence, namely the lexical item whose meaning has been made contextually more specific. Recanati (2017, pp. 219-220).

${ }^{14}$ John Collins (2019), who in his online-paper “On Saturation in Weather Reports” pushes towards a radical pragmatism is not convinced of Recanati's formulation of the weatherman example and offers another variant involving detectors all over the universe and including the assumption that the weatherman does not know if he is or not on Earth. Now, it seems to me that Recanati's answer to the proposal to fill up (by default) the argument slot with on Earth still applies to Collins' variant of raining on the Universe. Independently of the possible weatherman-variants, at the end of the paper I will come back to the dialogical view on radicalizing contextualism.
} 
computationally tractable aspects of language. ${ }^{15}$ The worry is that contextualism is committed to semantic flexibility (i.e. that the meaning of a word may vary from occurrence to occurrence, and, it may vary, in particular, as a function of the words it combines with). This amounts to acknowledging that the meaning of an expression may well not only depend upon the meaning of the complex in which it occurs, but it also may depend upon the meaning of the other words that occur in the same complex - e.g. the meaning of big in big mouse. Thus, from this perspective it follows that contextualism undermines compositionality. Recanati's (2010, chapter 1) solution, is to make the adjective dependent upon a context, that may be made explicit by linguistic means. For example, the contribution of big in big mouse, is rendered by the contribution of big in relation to the class of mice. Now, as discussed in the next section of the present paper, the introduction of CTT-notion of dependent-types seem to offer a straightforward approach to Recanati's interscective understanding of the contextual dependence of complex adjectives. Questions on compositionality are also involved in the availability constraint mentioned above, since the minimal proposition of propositional Minimalists is not computed at all in the modulation process. The very first available proposition understood form an utterance of a sentence is, on Recanati's view; one which is already composed by modulation.

The main aim of the present paper is to show that the recently developed dialogical approach to Martin-Löf's Constructive Type Theory (CTT), called Immanent Reasoning,

- provides, the means for distinguishing François Recanati's process of free enrichment and saturation;

- offers a straightforward approach to context-dependence that responds to compositionality worries. For short, Recanati's account of context dependent occasion meaning amounts to the introduction of dependent types (absent in Montague-style semantics);

- meets his own objections against perspectives based on unarticulated constituents;

- gives a straightforward response to the failure of third excluded in some important instances of faultless disagreement without giving up the notion of propositional content;

- opens a new venue to pragmatic modulation, where the dialogical speaker-receiver interaction is integrated into the notion of enrichment.

The proposed setting understands enrichment as operating on (contextually) proof-objects that make fully articulated event-propositions true. The point is that by distinguishing what makes a proposition true from the proposition made true offers a simple and clean way to avoid conflating the contextual elements that enrich a proposition with the proposition itself.

Such a framework abounds in means for expressing reference structures such as anaphora, including time and/or location reference. Indeed, a fundamental part of our proposal is to implement enrichment by the use of Arne Ranta's (1994, pp. 106-111) timing- and/or locativefunctions, that associate proof-objects to contextual elements (e.g. time moments or locations), instead Recanati's variadic functions - and which can be object of reference. In such a framework, neither before enrichment nor after enrichment does It is raining carry a free variable for events, or location and/or time, nor does timing assume quantifying over time moments.

\footnotetext{
${ }^{15}$ See Fodor $(2001,2003)$ and Bach $(2012)$, who also casts doubts on the of notion of context-dependece deployed by contextualists.
} 
According to this proposal, enrichment is a process of dialogical interaction by the means of which the relativization of a proposition is carried out by responding to questions on specifying the proof-object for that proposition epistemically assumed to be true.

More generally, the present paper suggests an alternative way to tackle the interface pragmatics semantics underlying the notion of pragmatic modulation by integrating into the interface the dialogical game of asking and giving reasons. This leads to the following points:

- Top-down processes in general and enrichment in particular are rights conferred by speaker to the receiver concerning an assertion of the former. They are meaning setting processes carried out from the receiver's point of view concerning the speaker's assertion.

- Bottom-up processes in general and saturation in particular are obligations contracted by the speaker concerning his own assertion. They are meaning setting processes carried out from the speaker's point of view concerning his own assertion.

The dialogical approach to contextualism, shares the view with Recanati's contextualism the rejection of propositional Syncretism. However, from the dialogical point of view the most basic form of propositional content, the proposition at the play-level, is not (necessarily) truthconditional. Moreover, the dialogical framework includes both a layer dealing with the context sensitivity of language, namely the play level, were meaning formation games intertwine with material games of asking and providing for (local) reasons, and a layer, namely the strategy level, that captures the logical and recursive aspects of language.

\section{Insights of Constructive Type Theory on Free Enrichment}

The most important source of resistance to the idea of pragmatic modulation is the fear that, if pragmatic modulation is allowed as a determinant of semantic content, the project of constructing a systematic, truth-conditional semantics for natural language, due to the instability or neverending feature of the process, will be doomed to failure - see Fodor (2001; 2003) and Cappelen and Lepore (2005). Recanati (2012, pp. 76) summarizes the arguments of his opponents in the following way:

In contrast to the contextual assignment of values to indexicals, modulation is not driven by the linguistic meaning of words. Nothing in the linguistic meaning of the words whose sense is modulated tells us that modulation ought to take place. Modulation takes place purely as a matter of context, of 'pragmatics'; what drives it is the urge to make sense of what the speaker is saying. So modulation is unsystematic. If we allow it as a determinant of semantic content, we make it impossible to construct a systematic theory of semantic content.

Recanati (2010, chapter 1, 2012, pp. 76-77) proposes to tackle this issue with the help of truth-conditional pragmatics based in the tenet that not only it is the case that pragmatics processes such as modulation are constitutive of meaning, but it also holds that their contribution to meaning can be shaped as a systematic compositional procedure. The idea is to defend the claim that compositionality holds at least in the minimal sense that the modulated meaning of the complex is a function of the modulated meanings of their parts (and the way they are put together) plus in addition, the context which determines how the content of the whole itself is modulated - Recanati (2010, p. 46). 
In his response to the objection of instability Recanati (2010, pp. 32-39) develops a procedure by the means of which, what the standing meaning - the meaning fixed by the semantic conventions of language, is contextually enriched to its occasion meaning - determined by the standing meaning and the context of utterance. More precisely, the occasion meaning of a word is the meaning which an occurrence of the word takes on in a particular context., not only in a particular linguistic context ${ }^{16}$ On his view this sharply contrasts with saturation that requires providing values to explicit or implicit variables. The point of Recanati's truth-conditional pragmatics is that the standing meaning of say, big, may contribute - in some compositional way - to big mouse, given that the occasion where the meaning of big is to be apprehended is the context of a relevant comparison class, namely the set of mice. However, the occasion meaning of big as ingredient of big mouse might be the context of a class of small living beings. In other words, according to the contextual theory underlying truth-conditional pragmatics the occasion meaning is understood as the context-dependent content of the expression, determined by (i) the standing meaning of the expression and (ii) the context of utterance - Recanati (2010, p. 39).

More generally; Recanati's (2010) truth-conditional pragmatics aims to show that pragmatic accounts of meaning do not lack per se the systematic means of formal model-theoretic semantics, despite the flexibility of meaning underlying modularity. Moreover, according to this account, at the end of a modularity process the proposition obtains a truth-conditional evaluation.

Thus, in such a framework, while the object of an enrichment process, the lekton, is said to fall short before determining absolute truth-conditions, in the sense that no truth-values can be assigned to it yet, the contextually enriched lekton does determine those conditions. Thus, though Recanati (2012) clearly recognizes that, in contrast to the standard approach to implicature, pragmatic modulation is not a post-semantic communicative addendum to the utterance of a sentence, it seems that Recanati endorses after all that a systematic account of compositionality of pragmatic modulation must be rendered compatible with model-theoretic semantics in the style of Montague grammar. However, this is not the only option to respond to the charge of being unsystematic.

In this context it might be worth exploring an approach that furnishes a systematic and compositional way to constitute instances of the type proposition before and after the enrichment and explain their formation during speaker-receiver interaction. Moreover the point is that we do not need to assume that truth-conditions are constitutive of meaning after all, but rather truthmaking conditions. ${ }^{17}$

We will develop our proposal in two main sections, in the present section, section 2, I will show how the CTT-notions of

\footnotetext{
${ }^{16}$ Recanati (2010, pp. 38-39)

${ }^{17}$ In fact, truth-making theory and CTT are quite different frameworks, but, in the present paper, in order to give a flavour of what a proof-object is, we will deploy evidence, truth-maker and proof-object as synonym. The main point of difference is that within CTT proof-object and proposition are conceived as enjoying a type-token relation: no token without type.
} 
- canonical and non- canonical proof-object of a proposition, avoid conflating the evaluation circumstance and the proposition, while respecting the type-token internal relation between proof-object and proposition.

- type-formation rules, and particularly the formation of dependent-types, render how the meaning of the parts of complex expressions are put together, and how they determine the dependent-proof objects (i.e. functions), that make the whole complex expressions true.

- complementary and adjunctive adverbials allow to shape the processes of saturation and enrichment

- assertions with tacit proof objects render the idea of tacit evaluation-circumstances

In section 3 of the present paper I will propose a dialogical setting for the relevant CTT distinctions that yields a dynamic perspective of Recanati's availability constraint. In such a dialogical setting, literal meaning is not processed first, as assumed by Minimalists, but is dialogically processed in parallel with the occasioning meaning determined by the formation rules of the play-level proposition at work

\subsection{Dependency, Independency and their Objects}

\subsubsection{Hypothetical and Categoricals}

One of the general philosophical tenets of CTT is linked to the task of avoid keeping content and form apart - Martin-Löf's (1984, p.2). ${ }^{18}$ More precisely, within Per Martin-Löf's constructive type theory (for short CTT), both, logical and non-logical constants are interpreted through the Curry-Howard correspondence between propositions and sets. A proposition is interpreted as a set whose elements represent the proofs of the proposition. It is also possible to view a set as a problem description in a way similar to Kolmogorov's explanation of the intuitionistic propositional calculus. In particular, a set can be seen as a specification of a programming problem, the elements of the set are then the programs that satisfy the specification - Martin-Löf (1984, p. 7). Furthermore, in CTT sets are understood also as types so that propositions can be seen as data (or proof-)-types. ${ }^{19}$

Additionaly, in the CTT framework it is possible to express at the object-language level

\section{A true or or $\vdash$ A or}

which, when asserted by some individual $\mathbf{g}$, conveys the information that this individual is in possession of some proof-object $a$ for $A$, a proof-object that makes $A$ true. Moreover, it can be rendered explicit by means of the categorical judgement

\footnotetext{
${ }^{18}$ Cf. Sundholm (1997, 2001)

${ }^{19}$ Cf. Nordström/Petersson/Smith (1990), Granström (2011).
} 
a: A,

which reads, there is a proof-object a of $A$ - or the individual $\mathbf{g}$ can bring forward the proofobject $a$ in support of his claim that $A$ is true. ${ }^{20}$

Summing up, within CTT a proposition is interpreted as a set the elements of which represent the proofs of the proposition, the solution to a problem, the fulfilments of an expectation. Accordingly,

\section{Explicit}

a: A

can be read as

$a$ is an element of the set $A$ $a$ is a proof of the proposition $A$ $a$ is a solution to the problem $A$ $a$ fulfils the expectation $A$

\section{Tacit}

A true or $\vdash$ A

One of the characteristic features of CTT is that it also allows, at the object-language level, expression of hypothetical judgements as a form of statement distinguishable from the assertion of the truth of an implicational proposition. Hypothetical judgements give rise to dependency structures in CTT, such as

$$
B(x) \operatorname{prop}(x: A)
$$

This is a formation rule for the hypothetical. More generally, formation rules, a distinctive feature of CTT, by the means of which semantic and syntactic features are processed together, establish well-typing rules.

The proof-object of an hypothetical judgment is a function:

$$
b(x): B(x)(x: A)
$$

which reads:

$b(x)$ is a (dependent) proof-object of $B(x)$, provided $x$ is a proof-object of the proposition $A$;

whereby the function $b$ takes elements from the set $A$, and yields proof-objects for $B(x)$.

In other words, in this frame the dependence of the truth of $B$ upon the truth of $A$ amounts to the dependence of the proof-object of $B$ upon the proof-object of $A$. And the dependence of the proof-object of $B$ upon the proof-object of $A$ is expressed by means of the function $b(x)$ (from $A$ to

\footnotetext{
${ }^{20}$ See Martin-Löf (1984, pp. 9-10). For a short introductory survey see Rahman, McConaughey, and Klev (2018, chapter II).
} 
$B$ ), where $x$ is a proof-object of $A$ and where the function $b(x)$ itself constitutes the dependent proofobject of $B$.

Thus, if we have $b(x): B(x)(x: A)$ as a premise, and we have as a second premise the fact that indeed that there is some evidence $a$ for the proposition $A$ (i.e., if we have as premise $a$ : $A$ ), then we can infer that $b(a): B(a)$.

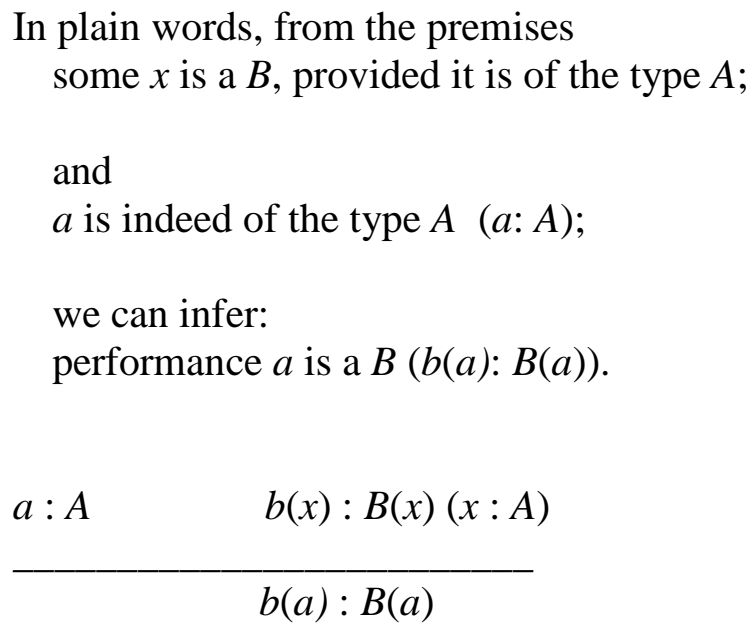

- Notice that the assertion $b(a): B(a)$, presupposes the formation $b(x): B(x)(x: A)$,.

In other words, the assertion $b(a): B(a)$ or even the tacit formulation $\vdash B(a)$, presupposes a suitable set $A$ that provides the element a occurring in the function that makes $B(a)$ true. It is the context of the assertion that determines what the suitable set is.

Let us apply these notions to some of Recanati's examples

\subsubsection{Recanati's Contextualism meets Type Theoretical Grammar}

The original work of Martin-Löf had as main aim to reconstruct (in the best possible way) informal mathematical reasoning. But, as already mentioned, Aarne Ranta (1994) applies CTT as a general theory on meaning and extended its use for the study of natural languages. Ranta (1994) shows in Type-Theoretical Grammar (TTG) how the original CTT- language for mathematical content can be extended to cover natural language phenomena such as pronouns, indexicality, anaphora, text-discourse analysis and temporal reference.

TTG seems to have the means to furnish a systematic framework for the delving into the inner structure of pragmatic modulation in general and of free-enrichment in particular. In the present paper we will focus on distinguishing free-enrichment from saturation, however let us very briefly discuss some of the salient examples involving compositionality.

\section{Occasion Meaning}


On big and small-mouses. As already mentioned, Recanati's take on the meaning of adjective constructions such as big mouse and small mouse is that their contextually enriched propositional content - resulting from applying a variadic function - is grounded, on intersective constructions such as the following

The set of all those $x$ that are both mice and big mice

The set of all those $x$ that are both mice and small mamifers

Recanati's point is that the choice of underlying domain, that set the comparative standards, is optional and contextually dependent. In the TTG framework this is rendered by the following formation rule, which render the dependency structure for the interserctive big mouse

$\operatorname{Big}(x): \operatorname{prop}(x:$ Mice) ;

which renders the predicate Big Mouse occurring in propositions such as

Some mice are big (mice)

( $\exists x:$ Mouse) $\operatorname{Big}(x)$

We can even add some more dependencies

Big mice are slow

$\vdash(\forall z:(\exists x$ : Mouse $) \operatorname{Big}(x)) \operatorname{Slow}(\operatorname{left}(z)$, or using the subset separation notation

$\vdash(\forall z:\{x:$ Mouse $\mid \operatorname{Big}(x)\}) \operatorname{Slow}(\operatorname{left}(z)$,

All those (elements of the set of) mice that are big, those are slow

In this notation, left is a projection function which extracts the left-side element of every $z$ that is both mouse and big (mouse): it select a big mouse. This construction is in fact a $\Sigma$ type and in the propositional interpretation it renders existentials. Similarly, right can be defined as the projection function which extracts the right-side element of every $z .{ }^{21}$ So if $z$, any of the big mice, is a compositum of the form $\langle x, b(x)>$ in which $x$ is an element of Mice and $b(x)$ is a method evidencing that $x$ can be described as being big mouse. Thus, left $(z)=\operatorname{left}(<x, b(x)>)=x$ : Mice and $\operatorname{right}(z)=\operatorname{right}(<x, b(x)>)=b(x): \operatorname{Big}(x)(x:$ Mice $)$.

The above construction can also be seen as involving an anaphora the head of which is one of those animals described as being a mouse. The tail of the anaphora is constituted by the projection function left $(\mathrm{z})$ which picks out those animals that are described as big mice in the grammatical subject and of which it is said that they are slow

${ }^{21}$ In fact, within TTG intersectivity of adjectives is a consequence of applying projection-rules to the pair that constitutes a proof-object of a $\Sigma$-type. 
Alternatively, if we wish to consider $\operatorname{Mouse}(x)$ as separating a subset from some domain, say, Rodents, we have the predicate

Big for those rodents that are mice

which can be deployed to build the proposition

Some of those rodents that are mice are big (mice)

$(\exists \mathrm{z}:\{x:$ Rodents $\mid \operatorname{Mouse}(x)\}) \operatorname{Big}(\operatorname{left}(\mathrm{z}))$

whereby, the projection left(z) selects one of those rodents that are mice

This seems to be close to what Recanati (2010, p. 35) has in mind when he deploys Mouse both as a predicate and as the underlying set over which Big for a Mouse is defined.

If the context provides a different set for comparing the size of our mice, say Mammals, then we can build the assertion

All those mammals that are mice are small (mammals)

$\vdash(\forall z:\{x$ : Mammals $\mid$ Mouse $(x)\})$ Small(left(z).

We can certainly add more layers, to produce All those mammals that are big mice are nevertheless small (mamals), without generating, to use Recanati’s (2007a, pp. 87-94, and 2017, pp. 220-24) terminology, genuine disagreement between interlocutors - at the end of the paper I will come back to Recanati's take on disagreement. Similar holds for cases such as $x$ likes $y$, whereby interlocutors might define like over quite different sets, e.g. the set of either human beings or the set of those human beings considered as suitable food (among cannibals), and so on - cf. Recanati’s (2010, p. 36).

I will however, leave it here and turn to the issue on how to systematize the difference between saturation and enrichment within TTG

\subsection{Adjunctive and Complementary Time Adverbials}

\subsubsection{Timing and Locative Functions}


Instead of starting with Recanati's (2007a,b) contrast between It is raining and It is raining now, ${ }^{22}$ let us for the moment consider first the following two examples of Ranta (1994): ${ }^{23}$

\section{1) Napoleon invaded Spain.}

2) The sun was shining.

Let us, for the sake of the comparison, take it that whereas the second sentence seems to require from the hearer to complete it with contextual elements that fix the time of that sun-shinning, in contrast to some other moments; the first one does not seem in principle to require any additional information. Indeed, it looks as the second sentence requires of the hearer to ask when?, where? in order to be grasp what is said, whereas the first sentence can, but does not need to be completed with the date of the invasion. This is the analysis followed by Ranta (1994) according to whom:

- The time adverbial that the sentence is endowed with in the first example is optional. In fact, such a kind of time adverbial is called in traditional grammar an adjunct. According to Ranta's TTG, the logical view on an adjunct is that of an operator turning a proposition into another proposition.

- The time adverbial that the sentence is endowed with in the second example is necessary. Within TTG, such adverbials constitute complements. As pointed out by Ranta (1994, p. 107) this may well not be the sense of complement in traditional grammar, but it is a complement in logical sense: it completes the expression with a time variable into a propositional expression

Thus, within Ranta's TTG the logical formation of an expression involving temporal reference declines in two main cases, namely:

1) Those cases where the expression is understood as a propositional function on a time scale of the form $A[t]$. The complement itself is the explicit or implicit time variable required in order to turn the propositional function into a proposition,:

$A(t): \operatorname{prop}(t:$ time $) \quad$ The sun was shining $(t): \operatorname{prop}(t:$ time $)$

$\vdash$ The sun was shining(11hs)

which is an implicit way to express that there is some kind of empirical method that renders the proposition The sun was shining(11hs) true, i.e. ,a function $b\left(t_{k}\right)$, that brings evidence for the proposition, that he sun was shining at some specific hour $t_{k}$ :

b(11hs): It is raining(11hs).

\footnotetext{
${ }^{22}$ In fact, as we will discuss furtheron, Recanati $(2007 a, b)$ would contest that the examples below are structurally different.

${ }^{23}$ In fact, the presentation of adjuncts and complements in TTG in the present section stemms from Ranta(1994, pp106-109).
} 
- Notice that the variable must occur in order to make of the expression The sun was shining, a proposition. ${ }^{24}$ The dependence of a proposition upon a variable (in this case a temporal one) is what makes of the time adverbial a complement.

2) Those cases where the expression is understood as a full-fledged proposition of the form $A$ (with no variable occurring in it, neither explicitly nor implicitly), that can but must not be endowed with an adjunct. The adjunct itself is constructed as a propositional function that times proof-objects (e.g. events) of $A$ by means of a timing function

A: prop $\quad$ Napoleon invaded Spain: prop

$\tau(x)$ : time $(x: A) \quad \tau(x)$ : time (x: Napoleon invaded Spain)

$\tau(a)$ : time, given that $a$, is the evidence of Napoleon's invasion of Spain.

thus, the timing function takes, the content of the proposition, the event, and times it. In our case $\tau=(a)$ evaluates to the year 1808 .

More generally expressions of the second kind constitute propositions the formation of which does not require time components. However, they can be temporally modified by means of adjuncts defined in terms of timing functions and equality - see Ranta (1994, p. 108). Thus, a temporally modified sentence, like

\section{Napoleon invaded Spain in 1808}

can then be analysed as the assertion constituted by the progressive conjunction of the event proposition that Napoleon invaded Spain and the identity-proposition (the adjunct) that the year of that event is indeed 1808:

$\vdash(\exists x$ : Napoleon invaded Spain $\left.) \tau(x)={ }_{\text {year }} 1808\right)$

$(a, b):(\exists x:$ Napoleon invaded Spain $) \tau(x)=$ year 1808$)$

whereby, $a$, is the evidence of Napoleon's invasion of Spain, and $b$ transforms this evidence into a proof that the timing of the invasion at stake is the year 1808 .

- Notice, that Napoleon invaded Spain expresses an independent proposition not dependent upon any variable

Keys to Notation: Recall that within CTT the formation of an existential is a kind of a anaphoric conjunction, such that the second element of the conjunction is dependent upon the first one. In our example, the pair that makes the existential true is composed by (i) the event that brings evidence of Napoleon's invasion of Spain and (ii) evidence that the timing of that event is 1808 . The notation $\tau(x)=$ year 1808 , stands for the identity relation $I(y e a r, \tau(x)$,

\footnotetext{
${ }^{24}$ Below, following Recanati (2002) we will distinguish between It is raining. and It is raining (here)
} 
1808): prop ( $x$ : Napoleon invaded Spain), defined within the set year - cf. Ranta (1994, p. $52)$.

\subsubsection{Enrichment and Saturation within TGG}

\subsubsection{Enrichment}

The reader has certainly already guessed that our proposal is to link the optional process of adding an adjunct to Recanati's free-enrichment; and to link the mandatory process of constituting a proposition out of a propositional function (with time and/or location variables) to Recanati’s saturation.

Furthermore, the TTG-analysis supports Recanati's claim that the lekton involved in freeenrichment is fully articulated: contextual adjunctives are added to complete expressions not to propositional functions. Moreover, it also supports the claim that the enriched proposition can be made true in a context but false in another.

Indeed, Recanati (2007a,b) contests that the logical form of expressions such as It is raining, implicitly assume some index that needs to be saturated. It is raining, concerns some indefinite context, in contrast the indexed It is raining here is about a particular context, namely the contextual value that saturates the variable constituting the indexical.

It is raining, conveys just that it is raining: it is raining punkt - Recanati(2007b, p. 132). However, It is raining, if further accuracy is required by the communicative context, might be enriched by locative and/or temporal indications deploying the same procedure we described for adding a temporal adjunctive to Napoleon invaded Spain. This explains how the enriched proposition can be true at some contexts and false at others.

For example, the logical form that results from enriching It is raining with It is raining in Lille at 12, s, as a response to when? and where? is the following:

$\vdash(\exists x:$ It is raining $) \kappa(x)={ }_{\text {City }}$ Lille $\wedge \tau(x)={ }_{\text {Hour } 12}$

, whereby instead of deploying only a timing function defined on the set Hour, we also have the locative function $\kappa(x)$ defined over the set City - as mentioned below Hour and City, will be introduced respectively as Time-Scales and Location-Scales defined over the locative and temporal dimensions Time and Location.

Thus, It is raining, says that there is some raining event, and it allows this assertion to be contextually understood as saying that this event takes place in Lille at 12 o'clock (or somewhere else) - in other words this assertion allows to understand the event as informing about the kind of change undergoing some place and time. Or to put it openly into Aristotelian terminology, the 
locative and timing functions turn raining-events into a specific kind of change that places at some time undergo - cf. Recanati (2002). ${ }^{25}$

This presupposes that the resulting enriched proposition is built upon the full-fledged proposition It is raining

$$
\kappa(x)={ }_{\text {Location } Z} \wedge \tau(x)={ }_{\text {Time }} \text { : prop }(x: \text { It is raining })
$$

given that rain-events $x$ are changes taking place at some location $z$ and time $w$ :

So we need to define the dimensions

Time: set

Location: set

Following Ranta (1994, p. 102) we shall display the sets Time and Location as involving several time scales and location scales, such as

$\begin{array}{ll}\text { Time: } \text { set } & \text { Location: } \text { set } \\ \text { year: set } & \text { continent: set } \\ \text { month: set } & \text { country: set } \\ \text { week: set } & \text { region: set } \\ \text { day: set } & \text { city: set } \\ \text { hour: set } & \text { town: set } \\ \text { minute: set } & \text { village: set }\end{array}$

The canonical elements of the set year are numbers. One can define dependencies such as the day 6 of December of 1960: (1917, December, 6): day - see Ranta (1994, pp. 102-103), and the village Coutiches in Nord-Pas-de-Calais in France (France, Nord-"Pas-de-Calais, Coutiches): village.

Thus enrichment as implemented by the timing and the locative functions, indeed achieve two tasks at the same time they add a new contextual parameter, such as Hour and City, and they add the corresponding dimension of those parameters, namely Time and Location, as envisaged by Recanati (2007, pp. 133-134). This is made clear if we write down the proof-objects that support the assertion:

\section{$(r, b):(\exists x:$ It is raining $) \kappa(x)={ }_{\text {City }}$ Lille $\wedge \tau(x)={ }_{\text {Hour } 12}$}

Indeed, that what provides the elements for the evaluation is a pair, constituted by $r$, and evidence $r$ for a raining-event and $b$ a function, a method, that does both adds a locative and temporal dimension and locates and times the raining event in a City at some precise Hour.

\footnotetext{
25 Indeed the dependence of time upon events expressed by $\tau(x):$ time $(x: A)$ comes close to the Aristotelian thesis that time is not something that can exist independently of (essential) change. Indeed, according to Aristotle's influential dictum time is the number of change in respect of before and after (Physics, IV, 219b 1-5) it makes no sense to speak of time during which there is no change at all.
} 


\subsubsection{Saturation}

In contrast to It is raining, the sentence

It is raining here, now,

once here and now are evaluated yields the following assertion, where the indexicals here and now have been saturated:

It is raining in-Lille at-12 true

, whereby, the formation indicates that we are in presence of a propositional function:

It is raining here $(c)$ now $(h)$ : prop (c: City, $h$ : Hour $)$, given here $\left(c_{\mathrm{i}}\right)=c_{\mathrm{i}}$ : City, and $\operatorname{now}\left(h_{\mathrm{i}}\right)=h_{\mathrm{i}}$ : Hour. ${ }^{26}$

In this case the evaluation of here $(c)$ and now $(h)$ turn the unsaturated propositional function It is raining here $(c)$ now $(h)$ into a proposition.

\subsubsection{Conclusion:}

According to Recanati's analysis the truth-making-conditions for both, It is raining and It is raining somewhere are the same (letting the time parameter aside). This might be one of the reasons behind Kölbel's (and others) worry that the lekton involved in enrichment and the one involved in saturation amount both to an Austinian proposition after all

Recanati's response involves the claim that the success of a communicative function of an assertion can be achieved without assuming that the asserted sentence (either explicitly or implicitly) articulates by some linguistic means the relative truth conditions imposed by a context for its truth-conditional evaluation. In our framework this comes up by the setting of the formation rules. Only the context can provide the suitable sets for building meaning dependencies.

Let us take, the sentence Everyone went to Lille: It is the context that indicates the formation rule should look like. Should it look like

went-to-Lille(x): prop (x: Human Being) or ?

went-to-Lille $(x, y)$ : prop ( $x$ : Human Being , $y$ : Student of Kuno Lorenz(x)), or ?

went-to-Lille $(x, \mathrm{z})$ : prop (x: Human Being , z: Red-Hair $(x))$ or?

went-to-Lille $(v, w)$ : prop ( $v$ : Elephant, w: White $(v)$ )

\footnotetext{
${ }^{26}$ The idea underlying the TTG approach to indexical expressions such a here, is that some location $c_{\mathrm{i}}$ has been fixed, so that here stands for the function $h e r e(c)$, so that if the variable $c$ is substituted by some fixed location $c_{\mathrm{i}}$, the function here $\left(c / c_{\mathrm{i}}\right)$ evaluates as $c_{\mathrm{i}}$. In our example, the location has been fixed as Lille, so that here in It is raining here, evaluates as It is raining in Lille - in the terminology of computer linguistics it is said that the sugaring of the function here(c) yields the natural language indexical expression here. Similar holds for the sugaring of now $(h)-\mathrm{cf}$. Ranta(1994, pp. 98-99 and p. 119).
} 
What is for sure is that the assertion

• Every Student of Kuno Lorenz went to Lille,

involving the specification

went-to-Lille $(x, y)$ : prop (x: Human Being , $y$ : Student of Kuno Lorenz $(x)$ )

is NOT an outcome of the assertion

เEvery Human-Being went to Lille,

- Even, if the formation of being a Student of Kuno Lorenz, presupposes that the predicate applies to Human Being.

The formation that enriches Human-Being to Human Being who is a Student of Kuno Lorenz, leading to the assertion Every Student of Kuno Lorenz went to Lille does not assume the preposterous detour of asserting Every Human-Being went to Lille.

So, though according to the TTG enrichment takes propositions as input it is not a form of Propositional Minimalism as promoted by Herman Cappelen, Ernie Lepore and Emma Borg.

\section{Enrichment and Immanent Reasoning: An Interactive Stance.}

Recanati's variadic functions deploy the Davidsonian approach to event-sentences. More precisely, notice that

- $\quad$ the sentence $\exists e[R A I N I N G(e)]$

is the result of saturating the propositional function

RAINING(e) : prop (e: EVENTS).

In contrast, according to the TTG analysis, a variable of the event type does not occur in the proposition itself, but in the assertion of the truth of it, as a proof-object.

In fact,

- $\quad$ according to the proposed TTG-analysis, the assertion expressed by the sentence It is raining operates on a full proposition not as a quasi-proposition in the waiting for contextual truth-condition. 
In the case of the weatherman, what makes the proposition It is raining true is indeed an event. Some rain-event is a truth-maker of the event-proposition It is raining: the rain event does

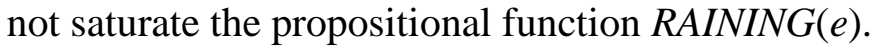

Moreover, the point of the weatherman scenario is that there is no direct evidence of a rain event, but an indirect one, namely a non-canonical proof-object for rain-events, the ringing of the bell. In CTT the execution of a non-canonical proof-object delivers a canonical one, in our case, executing the ringing of the bell, amounts to the process of verifying which detector triggered the ringing. However, the bare ringing of the bell allows the receiver to trigger an enrichment process that yields the assertion It is raining somewhere.

Notice that the particular enrichment processed by the receiver is totally dependent upon the specific proof-object brought forward by the speaker in the context of the weatherman-scenario. Certainly, as in Recanati's own framework, other contexts might involve different proof-objects that assume different formation rules.

Recall that the standard way of recognizing if we are or not in presence of an assertion involving a saturated propositional function is the mandatory feature of saturation as implemented by its proof-object - namely, a function that encodes the dependency structure at work. If the propositional function has not been saturated and the uttered sentence involves an incomplete proposition, then, from the communicative point of view, saturating the indexical is the speaker's duty.

However, in the current forms of Contextualism it looks as if the dialogical roles of speaker and receiver are not constitutive of the pragmatic modulation processes engaged in communicative interaction. If pragmatics should be constitutive of meaning this must be integrated into the framework.

To put it bluntly, from a dialogical point of view saturation obliges the speaker to fulfil hic et nunc, since it is him who undertook such a commitment by making it explicit that the content of his assertion is made dependent upon filling up the slots imposed by his use of the indexicals here and now. Dually the receiver has the right to ask the speaker to fulfil those slots in order the communicative interaction to succeed. Alternatively, the receiver, might be able to fulfil them by himself. However, in this case the receiver cannot choose a context at will, and must adopt the speaker perspective.

Enrichment goes the other way round, it is the receiver who will add or not a new temporal and or locative dimension. It is the receiver's perspective that prevails here. . In fact, it is the very notion of propositional content that requires to the thought from a dialogical point of view, particularly so if the framework should be able to integrate cases where truth-conditionality seems to fail - see Recanati (2017, pp. 222-224ç, Bach (2004, 2005, 2006).

More generally we need a framework for the notion enrichment where the notion of proposition, does not only integrate the dialogical interaction but it is not restricted to laying down absolute truth-making conditions - a restriction underlying the proof-theoretical framework of CTT. So what we would like is to have our cake, the TTG analysis of enrichment, and eat it, namely (1) a notion of proposition not restricted to validity - be it by proof-theoretical or truth-conditional 
means, (2) a differentiated approach to the meaning explanations of adjunctive and complementary temporal reference.

It is our claim that Immanent Reasoning delivers such and undertaking where enrichment involves a fully articulated proposition, defined at the play level, and clear dialogical meaning explanation for distinguishing enrichment from saturation in temporal contexts.

\subsection{The Dialogical Framework: A Pragmatist Approach to the Constitution of Meaning}

Dialogic logic was conceived as a pragmatist approach to meaning in logic that resorts to concepts of game theory such as winning a play and that of the existence of a winning strategy. Nowadays it has been extended to a general framework for the study of meaning, knowledge and inference constituted during interaction. The new developments include cooperative dialogues and dialogues deploying a fully interpreted language (dialogues with content"). ${ }^{27}$

According to the dialogical perspective, knowledge, meaning and truth are conceived as a result of social interaction, where, as recently pointed out by Per Martin-Löf (2017a,b), normativity is not understood as a type of pragmatic operator acting on a propositional nucleus destined to express knowledge and meaning, but on the contrary: the type of normativity that emerges from the social interaction associated with knowledge and meaning is constitutive of these notions. In other words, according to the conception of the dialogical framework, the intertwining of the right to ask for reasons, on the one hand, and the obligation to give them, on the other, provides the roots of knowledge, meaning and truth. ${ }^{28}$

\subsubsection{Local, Global Meaning and Strategies}

As hinted by its name, this framework studies dialogues; but it also takes the form of dialogues. In a dialogue, two parties (players) argue on a thesis (a certain statement that is the subject of the whole argument) and follow certain fixed rules in their argument. The player who states the thesis is the Proponent (for short $\mathbf{P}$ ), and his rival, the player who challenges the thesis, is the Opponent $(\mathbf{O})$. In challenging the Proponent's thesis, the Opponent is requiring of the Proponent that he defends his statement.

The interaction between the two players is spelled out by challenges and defences. Actions in a dialogue are called moves; they are often understood as speech-acts involving declarative utterances (assertions) and interrogative utterances (requests). The rules for dialogues thus never deal with expressions isolated from the act of uttering them.

\footnotetext{
${ }^{27}$ It was the philosopher and mathematician Paul Lorenzen who in the late 1950s was the first to introduce a gametheoretical approach to meaning in logic. Lorenzen (1958) called this semantics Dialogische Logik. Later, it was further developed by him and Kuno Lorenz - see Lorenzen and Lorenz (1978).

${ }^{28}$ This formulation aims to link the perspective of Robert Brandom with that of the logic of dialogue. See Mathieu Marion (2009, 2010). For a discussion about what they have in common and what distinguishes both approaches, see Rahman, McConaughey, Klev and Clerbout (2018, pp. 10-12):
} 
The rules in the dialogical framework are divided into two kinds of rules: particle rules and structural rules. Whereas the first determine local meaning, the second rules determine global meaning'.

Local meaning explains the meaning of an expression independently of the rules setting the development of a dialogue. Global meaning set the meaning of an expression in the context of some specific form of developing a dialogue.

More precisely:

Particle rules (Partikelregeln') determine the legal moves in a play and regulate interaction by establishing the relevant moves constituting "challenges". More precisely, a challenge is a move prescribed as being an appropriate attack to a previous move (a statement) and thus require that the challenged player play a moved indicates as the appropriate defence to that attack. If the challenged player defends his statement, he has answered the challenge.

Structural rules (Rahmenregeln) on the other hand determine the general course of a dialogue game, such as how a game is initiated, how to play it, how it ends, and so on. The point of these rules is not so much to spell out the meaning of the logical constants by specifying how to act in an appropriate way - this is the role of the particle rules-; it is rather to specify according to what structure interactions will take place. It is one thing to determine the meaning of the logical constants as a set of appropriate challenges and defences, it is another to define whose turn it is to play and when a player is allowed to play a move

According to the structural rules a play ends when it is a player's turn to make a move but that player has no available move left. That player loses, the other player wins.

Now, inferences and validity are defined in relation to a winning strategy for $\mathbf{P}$. However, notice the following point

- winning a dialogue (a play) is not enough for defining validity. Indeed, wining a play does not ensure validity. Dually losing, a play does not mean that the thesis is not valid.

What we need now is to define strategies.

\section{Winning Strategy}

- A player $\mathbf{X}$ has a winning strategy if for every move made by the other player $\mathbf{Y}$, player $\mathbf{X}$ can make another move, such that each resulting play is eventually won by $\mathbf{X}$.

In dialogical logic validity is defined in relation to winning strategies for the proponent $\mathbf{P}$.

- A winning strategy for $\mathbf{P}$ for a thesis $A$ is a tree $\boldsymbol{S}$ the branches of which are plays won by $\mathbf{P}$, where the nodes are those moves, such that 
i. S has the move $\mathbf{P} A$ as root node (with depth 0 ),

ii. if the node is an $\mathbf{O}$ - move (i.e. if the depth of a node is odd), then it has exactly one successor node (which is a $\mathbf{P}$-move),

iii. if the node is a $\mathbf{P}$-move (i.e. if if the depth of a node is even), then it has as

many successor nodes as there are possible moves for $\mathbf{O}$ at this position.

- One crucial point is that, different to proof-theory, the notion of proposition is not defined top-down, from validity (a $\mathbf{P}$-winning strategy) but bottom-up from the play-level. Thus, the notion of proposition is not defined at the strategy level. In other words it is neither the proof-theoretical level nor the distribution of truth values that yields the dialogical notion of proposition but winning and losing a single finite play.

\subsubsection{Dialogue-Definiteness and Propositions}

As already mentioned, the dialogical approach to meaning is structured in three levels, (i) that of the local meaning (determined by the particle rules for the logical constants), (ii) that of the global meaning (determined by the structural rules), and (iii) that of the strategic level of meaning (determined by what is required for having a winning strategy). A characteristic of the local meaning is that the rules are player independent: the meaning is thus defined in the same fashion for each player; they are bound by the same sets of duties and rights when they start a dialogue. This normative aspect is thus constitutive of the play level (which encompasses both the local meaning and the global meaning): it is even what allows one to judge that a dialogue is taking place. In this regard, meaning is immanent to the dialogue: what constitutes the meaning of the statements in a particular dialogue solely rests on rules determining interaction (the local and the global levels of meaning). The strategy level on the other hand is built on the play level, and the notion of demonstration operates on the strategy level (it amounts to having a winning strategy).

Two main tenets of the dialogical theory of meaning can be traced back to Wittgenstein, and ground in particular the pivotal notion of dialogue-definiteness:

1. the internal feature of meaning (the Unhintergehbarkeit der Sprache, ${ }^{29}$ ) and

2. the meaning as mediated by language-games.

I

If we relate the notion of internalization of meaning with both language-games and fullyinterpreted languages of CTT, then a salient feature of the dialogical approach to meaning can come to fore: the expressive power of CTT allows all these actions involved in the dialogical constitution of meaning to be incorporated as an explicit part of the object-language of the dialogical framework.

In relation to the second tenet, the inceptors of the dialogical framework observed that if language-games are to be conceived as mediators of meaning carried out by social interaction, these language-games must be games actually playable by human beings: it must be the case that

${ }^{29}$ See Tractatus Logico-Philosophicus, 5.6. 
we can actually perform them, ${ }^{30}$ which is captured in the notion of dialogue-definiteness. ${ }^{31}$ Dialogue-definiteness is essential for dialogues to be mediators of meaning, but it is also constitutive of what propositions are, as Lorenz clearly puts it:

[...] for an entity to be a proposition there must exist an individual play, such that this entity occupies the initial position, and the play reaches a final position with either win or loss after a finite number of moves according to definite rules. Lorenz (2001, p. 258).

A proposition is thus defined as a dialogue-definite expression, that is, an expression $A$ such that there is an individual play about $A$, that can be said to be lost or won after a finite number of steps, following given rules of dialogical interaction.

The notion of dialogue-definiteness is in this sense the backbone of the dialogical theory of meaning: it provides the basis for implementing the human-playability requirement and the notion of proposition.

Furthermore; Dialogue-definiteness sets apart rather decisively the level of strategies from the level of plays, as Lorenz's notion of dialogue-definite proposition does not amount to a set of winning strategies, but rather to an individual play.

Within the framework of Immanent Reasoning - Rahman et al. (2018), dialoguedefiniteness is further worked out by integrating the dialogical articulation of propositions and their justifications. More precisely, the articulation of propositions and their justifications is spelled out by prescribing how to introduce reasons in order to justify a challenged claim, and how to analyse a reason that justifies a claim.

\subsection{Immanent Reasoning}

\subsubsection{Some relevant notions}

Local Reasons: Dialogues are games of giving and asking for reasons; yet in the standard dialogical framework, the reasons for each statement are left implicit and do not appear in the notation of the statement: we have statements of the form $\mathbf{X} ! A$ for instance where $A$ is an elementary proposition. The framework of dialogues for immanent reasoning allows to make explicit the reason for making a statement, statements then have the form $\mathbf{X} a: A$, where $a$ is the (local) reason $\mathbf{X}$ has for stating the proposition $A$. But even in dialogues for immanent reasoning, all reasons are not always provided, and sometimes statements have only implicit reasons for bringing the proposition forward, taking then the same form as in the standard dialogical framework: $\mathbf{X} ! A$. Notice that when (local) reasons are not explicit, an exclamation mark is added before the proposition: the statement then has an implicit reason for being made.

\footnotetext{
${ }^{30}$ Cf. Marion (2006, p. 245) .

31 The fact that these language-games must be finite does not rule out the possibility of a (potentially) infinite number of them.
} 
The most basic contribution of a local reason is its contribution to a dialogue involving an elementary proposition. Informally, we can say that if the Proponent $\mathbf{P}$ states the elementary proposition $A$, it is because $\mathbf{P}$ claims that he can bring forward a reason in defence of his statement, it is this reason that provides content to the propositional expression.

Local-meaning - analysis and synthesis: The local meaning of such statements results from the rules describing how to compose (synthesis) within a play the suitable local reasons for the proposition $A$ and how to separate (analysis) a complex local reason into the elements required by the composition rules for $A$. The synthesis and analysis processes of $A$ are built on the formation rules for $A$.

Formation: It is presupposed in standard dialogical systems that the players use well-formed formulas (wff). The well formation can be checked at will, but only with the usual meta reasoning by which one checks that the formula does indeed observe the definition of a wff. We want to enrich our CTT-based dialogical framework by allowing players themselves to enquire on the formation of the components of a statement within a play.

For a condensed overview on how to develop this framework for logic and beyond logic see Rahman (2019). In the next section, we launch a first exploration on how to provide meaning explanations for enrichment and saturation within Immanent Reasoning

\subsubsection{Dialogical meaning explanations for Enrichment and Saturation}

Since, as shown below, the dialogical interaction leading to enrichment is cooperative rather than competitive it seems better to think of $\mathbf{X}$ and $\mathbf{Y}$ as Speaker and Receiver, rather than Proponent and Opponent.

By the same token it is the case that during such a form of cooperative interaction, some responses to previous moves, are neither challenges nor defences but moves aimed at specifying the propositional content involved in the claim, we speak of response and request.

\section{Enrichment}

The canonical dialogical meaning explanation of enrichment is based on the idea that adjoining a suitable context is a choice (in general by the Receiver). This also entails that the original claim is understood as a full-fledged proposition on the grounds of which other assertions can be grounded (even if the temporal and/or locative contextual parameters of the original claim are left unspecified). In such a setting the meaning explanation of enrichment has the following features:

1) The moves of the Receiver are Responses, whereby the evidence that is brought forward as evidence for rain is specified by means of adding a context.

2) It is the Receiver who can choose to specify the context. The Receiver might propose one location and, possibly, if requested by the Speaker, a temporal indication might be added - by default the temporal reference of the Speaker's utterance. 
3) The Receiver might ground some of his further assertions in the original, not enriched claim of the Speaker. More precisely the Receiver might ground his own assertion We should stop using up the water of the reservoirs on the Speaker's assertion It is raining. Here the Receiver relies on the Speaker's Authority. This kind of move has been called by Göran Sundholm (19997) called an Epistemic Assumption. Martin-Löf () suggested to endow it with a dialogical reading- See. Martin-Löf (2015), and Rahman/McConaughey/Klev/Clerbout (2018, pp. vii-xii)

This yields the following rules of local meaning

\begin{tabular}{|c|c|}
\hline $\begin{array}{l}\text { Enrichment } \\
\text { Claim }\end{array}$ & $\begin{array}{c}\text { Enrichment } \\
\text { Response }\end{array}$ \\
\hline & $\begin{array}{c}\mathbf{1} \mathbf{1}) \\
\mathbf{Y} \text { ? reason } \\
\text { (on what grounds?) } \\
\mathbf{X} r \text { : It is raining } \\
\mathbf{Y} !\left(\exists x \text { : It is raining ) }\left(\exists c \text { : City) } \kappa(x)==_{C i t y} C\right.\right. \\
\text { object ringing of the bell) } \\
\text { Or } \\
\mathbf{Y} !\left(\exists x \text { : It is raining ) } \kappa(x)={ }_{C i t y} L i l l e\right. \\
\text { (this response assumes that } r \text { is the non canonical proof- } \\
\text { for identifying the location specific to the rain event at } \\
\text { stake) }\end{array}$ \\
\hline \multirow[t]{2}{*}{$\mathbf{X}$ ! It is raining } & Or \\
\hline & $\begin{array}{l}\text { (2) } \\
\mathbf{Y} \text { !. We should stop using up the water of the reservoirs } \\
\text { (this response assumes that the receiver takes the } \\
\text { weatherman's at face value. The receiver makes an } \\
\text { epistemic assumption). }\end{array}$ \\
\hline
\end{tabular}

Notice too that no winning-strategy is required. A play is sufficient. In fact, every play, might be built on a different choice of the Receiver for enriching or not the original claim, such as, Paris, Bahía Blanca, Sevilla. Moreover, the specification is defeasible, and might thus be revised in the further development of the dialogical interaction, triggering different plays. This is not a problem at all for the dialogical approach: a full and sound notion of proposition requires dialoguedefiniteness not truth-conditionality. 


\section{Saturation}

The canonical dialogical meaning explanation of saturation is based on the idea that the choice of completing the claim with a context is enforced by the indexical. This also entails that the original claim can only by understood as a full-fledged proposition iff the variable constituting the indexical has been evaluated with the suitable contextual parameters. Thus the canonical meaning explanation of saturation in a dialogical setting has the following features:

1. The moves of the Receiver are Requests, whereby the evidence that is brought forward as evidence for rain is specified by means of making explicit the time and place of utterance.

2. Neither Receiver nor Speaker can choose a context other than place or time of utterance of the Speaker's assertion.

3. Requests indicate that such a move is necessary in order the Receiver to draw further inferences.

This yields the following rules of local meaning

\begin{tabular}{|c|c|c|}
\hline $\begin{array}{c}\text { Indexical } \\
\text { Claim }\end{array}$ & $\begin{array}{c}\text { Saturation } \\
\text { Request }\end{array}$ & $\begin{array}{c}\text { Saturation } \\
\text { Response }\end{array}$ \\
\hline $\mathbf{X}$ ! It is raining here & $\begin{array}{c}\mathbf{Y} \text { ? here(Lille), given Lille: City } \\
\text { (we were talking about Lille, so } \\
\text { here must be Lille) }\end{array}$ & $\mathbf{X}$ ! It is raining here(Lille) \\
\hline
\end{tabular}

Notice that also in this case no winning-strategy is required. A play is sufficient. However, what the formation presupposes is the following

- It is raining here(c): prop (c : City)

Notice too that the salient feature of saturation is that the Receiver, must request the evaluation in order to continue the interaction. He cannot simply respond, he must before have the saturation of the indexical

Expressions with implicit free variables require formation moves even before starting

\begin{tabular}{|c|c|c|}
\hline Claim & Request & Response \\
\hline $\mathbf{X}$ ! John finished & Y ? Formation & $\mathbf{X}$ ! John finished $(x)$ : prop $(x:$ \\
& writing $).$ \\
\hline
\end{tabular}

\subsection{Brief Remarks on Faultless Disagreement. Propositional Content without Third-Excluded}


Recanati's (2017, pp. 220-224) response to some objections raised by Max Kölbel (2017, pp. 210-220) on the analysis of faultless disagreement suggested in Perspectival Thought provides an excellent opportunity to illustrate one of the main points of the present paper. More precisely, it shows how to handle within Immanent Reasoning instances where though third-excluded (at the strategic level) fails, genuine propositional content is still present and governs dialogical interaction. ${ }^{32}$

By the way the whole issue seems to be closely related to the rich and large debates on relativism in Ancient Greece. More precisely, Recanati's and Kölbel's discussion on faultless disagreement recalls some of the debates of Protagoras's Relativism in several parts of Plato's Theatetus. ${ }^{33}$ I will not develop herewith a study of the ancient sources, though I think this is a crucial pending task to which I hope to come back in the near future.

\subsubsection{Sustained Disagreement as Prescriptions.}

In Perspectival Thought Recanati (2007a, pp. 87-94) proposes to study agreement and disagreement as involving complete content (involving the lekton and the situation of evaluation). The point is that if two people entertain the same lekton but evaluate it with respect to distinct situations, no genuine disagreement takes place. However, faultless disagreement seems to pose a problem to Recanati's approach. Moreover, Kölbel (2017) brings forward the case of sustained disagreement, where neither of the interlocutors are prepared to change their minds, though no misunderstanding takes place. Recanati's (2017) response is to understand cases of sustained disagreement as prescriptions to adopt some common evaluation standards. Since prescriptions do not, in the standard view, satisfy truth-conditions, third-excluded fails:

Faultless disagreement seems to be a counterexample: people who disagree about e.g. matters of taste seem to evaluate the same lekton (e.g. the relativized proposition that Vegemite is tasty) with respect to their respective standards of taste, and end up with distinct truth-values when the standards are sufficiently different. Thus Vegemite is tasty to you, but not to me. You say 'Vegemite is tasty'; I respond: 'No, it is disgusting'. The disagreement here seems genuine, but there is no complete content which the discussants share and over which they disagree. They only share the lekton (that Vegemite is tasty) but evaluate it with respect to their respective standards. The complete contents of their respective thoughts are therefore different: subject A evaluates the lekton with respect to A's standards of taste (and ends up with the value 'true'), while B evaluates the same lekton with respect to B's different standards (and ends up with the value 'false'). So what is going on? What explains the difference between the 'it's raining' case, in which there is no genuine disagreement, and the Vegemite case, in which it seems that there is?

[...] 'Vegemite is tasty' has an objective flavour (in many contexts at least) while 'Vegemite is tasty to me' or 'I find it tasty' are more subjective. According to Perspectival Thought, what accounts for the objective flavour of 'Vegemite is tasty' is the fact that the relevant judge is the community to which both the speaker and the hearer belong. [...].

This leaves many possible options for analysing alleged cases of faultless disagreement. First, when A says 'Vegemite is tasty' and B responds 'it is not', A may be wrong in presupposing that her standard of state regarding

\footnotetext{
${ }^{32}$ Other interesting instances of such kind of phenomena are being discussed in Chakraborti \& Lion (2019), in their contribution to the present volume.

${ }^{33}$ I had the chance to be reminded of these debates during the inspiring session of the seminar on the Theaetetus held at the laboratory STL: UMR 8163, Univ. Lille on the $14^{\text {th }}$ of November 2019. The meeting of that date was held by Philippe Rousseau and Thomas Bénatouil and focused on the Theaetetus. (170a-171d and 171e-174a). The seminar is organized by Thomas Bénatouïl and Claire Louget.
} 
Vegemite is shared by the community. B's dissenting voice suggests that the standard may actually not be shared. If that is so, then A is at fault (and must retreat to the subjective statement 'I find it tasty'). Second, $A$ is free to maintain his statement regardless of B's dissension, by suitably adjusting 'the community' and excluding B from it. For example, A may judge that B departs, by his bad taste, from the standards of the community. If this is true, then, from A's point of view, B is at fault. However we interpret the case, the disagreement is not faultless.

I agree with Kölbel that there are also cases of a third type: cases of 'faultless disagreement' such that no failure whatsoever is involved on the part of either speaker or hearer. The protagonists may enter an episode of sustained disagreement in which both parties (re)affirm diverging views without ever retreating to a weaker, subjective statement of their taste

[...]I propose that, in sustained disagreement about matters of taste, the interlocutors's moves and countermoves ('Vegemite is tasty', 'no, it is disgusting') are (i) neither true nor false, yet (ii) perfectly felicitous (involving no 'failure'). [...]. In sustained disagreement the interlocutors negotiate the standards for the local community they form. I propose that their utterances (e.g. 'Vegemite is tasty') are not assertions but prescriptions, inviting the hearer to adopt standards with respect to which the lekton is true. The speaker offers her own standards as the coordinative standard for the community.

[...]

When the utterance is a prescription the content of the speech act is a relativized proposition (lekton): that Vegemite is tasty. The speaker tries to get the hearer (and the local community more generally) to adopt standards which make that lekton true. The lekton has truth-at conditions (it is true at certain standards and false at others) but it carries no absolute truth-conditions in these circumstances, for lack of a communal standard accepted by all parties. The conversation aims at establishing such a standard. Until it is settled, no determinate, stable situation of evaluation is provided to turn the lekton into a full Austinian proposition. The speech act is nondefective, however. It has a determinate force and a determinate content (the lekton) but, like orders, it does not allow for truth-evaluation. Recanati (2017, pp. 220-223).

\subsubsection{Dialogical Perspectives on Sustained Disagreement.}

As mentioned above, according to the dialogical perspective, knowledge, meaning and truth are conceived as a result of interaction. Thus form the dialogical point of view prescriptions are constitutive of meaning - see Per Martin-Löf (2017a,b). Interesting is that this prescriptive feature does not prevent the framework to shape both a logic with and without third-excluded. In the case of disagreement, third-excluded holds iff one of the interlocutors withdraws from his initial claim and adopts the position of the other and the disagreement is solved. But certainly, this cannot be granted in general, and does not count as an instance of sustained disagreement.

Let us start with our general approach to enrichment. Assume there are two incompatible standards for evaluating the beauty of a painting, and that for each of these standards there is a function that provides some evaluation supporting the initial assertion - I will not here introduce a measurement order. The evaluation functions are the ones that implement the enrichment of the initial assertion in a similar way as in the case of It is raining.

$\varepsilon_{1}(x): S_{1}$ (x: This Painting is beautiful), given This Painting is beautiful: prop.

$\varepsilon_{2}(x): S_{2}(x$ : This Painting is ugly), given This Painting is ugly: prop

Let us assume too that ugly and beautiful are incompatible 
So, we might have the following dialogue, where for the sake of simplicity I ignore the anaphoric reference "It is ugly" and simply assume that the anaphora reference is present in This Painting is ugly.

Speaker: This Painting is beautiful!

Audience: No: This Painting is ugly!

! ( $\exists x$ : This Painting is ugly) $\left(\exists z: S_{2}\right) \varepsilon_{2}(x)=_{S 2 Z}$

Now, there are three possibilities:

1. The Speaker adopts the standards of the Audience, and accepts the proposed enrichment.

In dialogical logic such kind of move amounts to coming back, or withdrawing - a move that differentiates classical logic from intuitionistic logic, whereby in the latter withdrawing is not allowed. Thus, in classical setting third-excluded amounts to adopting the challenger's view.

2. The Speaker rejects the Audience's proposal and proposes the enrichment ! ( $\exists y$ : This Painting is beautiful) $\left(\exists w: S_{1}\right) \varepsilon_{1}(y)=_{S 1} w$

This might continue until some end has been achieved without any of both giving up their minds.

3. After a while a new standard is agreed upon which a decision can be taken. Notice that in our framework the input of an enrichment is a proposition, the further development does not prevent the initial claim of having propositional content.

Now, the most interesting case is the intermediate one. Recall that, crucial to the notion of propositional meaning in dialogical logic is that each play must be finite, though there might be a infinite number of those plays. So, in any of these infinite plays, one of the interlocutors wins. However, this does not mean that there is a winning strategy since, it might well be that he loses in others. Moreover, each of the plays might engage different standards that might have different outcomes.

We can certainly adopt a global look, from the outside and formulate that whole as an hypothetical, where it is not granted that either of the sides of the disjunction can be made true, and whereby the two sides are incompatible. Let " $P B$ " stand for "This Painting is beautiful" and " $P U$ " for "This Painting is ugly", " $=_{\{H\}}$ " for identical within the hypothesis, that is within the disjunction; and let "first ${ }^{\vee}(y)$ " stand for the injection that selects an element of PB and renders the disjunction true by providing a proof object for its left side. Similar holds for $\operatorname{second}^{\vee}(z)$

$b(x):(\forall y: P B)\left[\right.$ first $\left.^{\vee}(y)=_{\{H\}} x \supset\left(\exists w: S_{1}\right) \varepsilon 1(y)=_{S 1} w\right] \wedge(\forall z: P U)\left[\operatorname{second}^{\vee}(z){ }_{\{H\}} X \supset(\exists z:\right.$

$\left.\left.S_{2}\right) \varepsilon_{2}(x)={ }_{S 2} Z\right](x: P B \vee P U)$

Which admits the gloss:

Under the hypothesis that the painting is either beautiful or ugly, if some evidence can be brought forward in favour for the claim that the painting is beautiful, then there is some suitable 
evaluation-method against which the claim is backed. Similar holds if the evidence backs the ugliness of the painting at stake. Propositional content is granted, since we can lay down the assertion-conditions for each claim, however third-excluded is not granted,

The global view is proof-theoretic and does not require the play-level. In either way, locally or globally, this case of faultless disagreement does not seem to require incomplete Austinian propositions.

\section{Conclusions and Work ahead}

From the dialogical point of view Recanati's (2007b) point on the un-shiftability of the contextual saturation of indexical expressions amounts to the fact that players do not have the choice for evaluating indexicals. Moreover, the saturation process must be completed before further assertions grounded on claims involving indexical expressions can be brought forward. This strongly contrasts with enrichment, where the specification process can take place or not, even for making further assertions.

This is linked to the point that from the dialogical point of view, the proposition occurring in a claim that can be enriched is a full-fledged one, even at the play-level where no absolute truthmaking conditions are laid down. Another way to put it is that whereas the formation of an anaphoric construction at work in a process of enrichment has a proposition (It is raining) as head of the anaphora; in a process of saturation the It is raining here constitutes the tail of an anaphoric construction with a type dependent upon a set from which here gets its value.

What syncretic propositionalism gets it wrong, is that it assumes that contextualisation processes take as input the proposition asserted in the utterance. But enrichment starts at a deeper level, meaning constitution as set by the formation rules. Modulating Everyone went to Lille, starts by laying down the formation of the quantified expression, namely went to Lille: prop ( $x$ : Student in this Seminar). This assumes a framework that includes hypothetical assertions, assertion involving dependent types. Enrichment affects the formation rules for the constitution of meaning

As already mentioned, the present paper is only a first exploration. There are many issues that need to be further studied, including, a large study of the different forms the anaphoric constructions can take, time-aspects, and exploring further the case of faultless disagreement.

Historic studies are also a further important pending research task, particularly so in relation to the notion of lekton. Moreover, perhaps we should distinguish the linguistic expression of a lekton (such as a pronouns, and indexicals) from its ontological side, the function - cf. Bronowski (2019).

All of this pending research tasks, should contribute to further explore the main idea underlying our approach: a genuine pragmatist approach to meaning can be developed from the dialogical stance on communicative interaction. 


\section{Acknowledgments.}

Many thanks to Teresa López-Soto (Sevilla) the editor of present inspiring volume and to the Laboratory STL: UMR-CNRS 8163 and particularly so Leone Gazziero (STL), Laurent Cesalli (Genève), leaders of the ANR Project SEMAINO (STL) and Claudio Majolino (STL), associated researcher to that project, for fostering the research leading to the present study.

The pluri-disciplinary STL-seminar on Plato’s Theaetetus lead by Thomas Bénatouïl (U. Lille ) and Claire Louget (U. Lille) offered a forum for rich and inspired discussions on subjects relevant to Contextualism, particularly so on the challenges of Protogoras relativism. I am very thankful for all the participants who helped me to reflect on the philosophical and historical roots of Contextualism.

Many thanks too, to Zoe McConaughey, Clément Lion, and Vincent Wistrand, doctorates at a the department of philosophy at University of Lille and members of the laboratory UMR: 8163, STL and who contributed my many fruitful discussions. 


\section{References}

Aristotle (1936).

Aristotle's Physics. A revised text with introduction and commentary. W. D. Ross. Oxford: Oxford Clarendon Press.

Bach, K. (2001).

“You don’t say?”. Synthese, vol. 128, pp. 15-44.

Bach, K. (2004).

"Minding the gap”. In C. Bianchi (ed.), The Semantics/Pragmatics Distinction. Stanford: CSLI

Publications, pp. 27-43.

Bach, K. (2005).

“Context ex Machina”. In: Z. G. Szabó (ed.), Semantics versus Pragmatics. Oxford: Clarendon Press, pp. $15-44$.

Bach, K. (2006).

"The excluded middle: Semantic minimalism without minimal propositions". Philosophy and Phenomenological Research, vol. 73 (2), pp. 435-442.

Bach, K. (2012)

“Context-Dependence (as it is)”. In M. García Carpintero \& M. Kölbel (eds.), The Continuum Companion to the Philosophy of Language. London: Continuum International Publishing Group, pp. 153-184.

Borg, E. (2004).

Minimal Semantics. Oxford: Oxford University Press.

Bronowski, A. (2019).

"What is wrong with lekta? Ancient critics of Stoic logic and language". In Methodos, vol. 19 . Special number Dire et vouloir dire dans les arts du langage anciens et tardo-antiques, edited by L. Gazziero. https://journals.openedition.org/methodos/5276.

Cappelen, H. and Lepore, E. ( 2005).

Insensitive Semantics. A Defense of Semantic. Minimalism and Speech Act Pluralism. Oxford: Blackwell.

Chakraborty, R. \& Lion, C. (2019).

"Two Convergences to Dynamic Formalism: Bakhtin's Dialogism and Brouwer's Creating Subject.”. In the present volume.

Collins, J. (2019)

"On Saturation in Weather Reports". Online https://www.academia.edu/6566639/

Chapter_3_On_Saturation_in_Weather_Reports

Depraetere, I. and Salkie, R. (2017).

Semantics and Pragmatics: Drawing a Line. Cham: Springer.

Dummett, M. (1997)

"Existence, Possibility and Time”. In G. Meggle (Ed.), Analyomen, Berlin: De Gruyter, vol. 2/1, pp. 43-67.

Elbourne, P (2008)

“The Argument from Binding”. Philosophical Perspectives, vol. 22, pp. 89-110.

Fodor, J. (2001).

"Language, Thought and Compositionality”. Mind and Languange, vol. 16, pp. 1-15

Fodor, J. (2003).

Hume Variations. Oxford: Oxford University Press.

Gabriel, G. \& Hülser, K. \& Schlotter, S. (2009)

"Zur Miete bei Frege - Rudolf Hirzel und die Rezeption der stoischen Logik und Semantik in Jena".

,History and Philosophy of Logic, vol. 30 : 4, pp . 369-388.

Grant, R (2019)

"Contextualism: What it Gets Wrong”. Online https://www.academia.edu/20122529/

Contextualism What it Gets Wrong

Kölbel, M. (2017).

“About Concerns”. In I. Depraetere \& R. Salkie (Eds.), Semantics and Pragmatics: Drawing a Line. Cham: Springer, 2017, pp. 197-214.

Lorenz, K. (2001). "Basic Objectives of Dialogue Logic in Historical Perspective”. Synthese, vol. 127(1-2), pp. 225263.

Lorenzen, P. (1958). 
“Logik und Agon”. Arti del XII Congresso Internationale de Filosofia, pp. 187-194.

Lorenzen, P., \& Lorenz, K. (1978).

Dialogische Logik. Darmstadt: Wissenschaftliche Buchgesellschaft.

Marion, M. (2006).

"Hintikka on Wittgenstein: from Language Games to Game Semantics”. In T. Aho, \& A.-V. Pietarinen (Eds.), Truth and Games: Essays in Honour of Gabriel Sandu X. Helsinki: Acta Philosophica Fennica, pp. $237-256$.

Marion, M. (2009).

“Why Play Logical Games?”. In O. Majer, A. V. Pietarinen, \& T. Tulenheimo (Eds.), Logic and Games: Unifying Logic (pp. 3-26),. Dordrecht: Springer.

Marion, M. (2010). “Between saying and Doing: From Lorenzen to Brandom and Back”. In P. E. Bour, M. Rebuschi, \& L. Rollet (Eds.), Constructions: Essays in Honour of Gerhard Heinzmann (pp. 489-497). London: College Publications.

Marti, L. (2006)

“Unarticulated Constitutents Revisited”. Linguistics and Philosophy, vol. 29, pp. 135-166.

Martin-Löf, P. (2014).

“Truth of empirical propositions”? Lecture held at the University of Leiden, February 2014. Transcription by Amsten Klev.

Martin-Löf, P. (2015).

"Is logic part of normative ethics?" Lecture Held at the research Unity Sciences, Normes, Décisions (FRE

3593), Paris, May 2015. Transcription by Ansten Klev.

Martin-Löf, P. (2017a).

“Assertion and Request”. Lecture held at Oslo, 2017. Transcription by Ansten Klev.

Martin-Löf, P. (2017b).

“Assertion and Request”. Lecture held at Stockholm. Transcription by Ansten Klev.

McConnell-Ginet, S. (1982)

“Adverbs and Logical Form”. Language, vol. 58, pp. 144-184

Partee, B. (1989)

"Binding Implicit Variables in Quantified Contexts". Proceedings of the Chicago Linguistic Society (CSL), vol. 25, pp. 342-365.

Perry, J. (1986)

“Thought Without Representation”. Supplementary Proceedings of the Aristotelian Society, vol . 60, pp. 263283.

Quine W. v. O. (1960).

"Variables Explained Away". In W. v. O. Quine, Selected Logic Papers, Cambridge Mass: Harvard University Press, 1995, pp. 227-35.

Ranta, A. (1994).

Type Theoretical Grammar. Oxford; Oxford Clarendon Press.

Rahman, S. (2019)

"Dialogues, Reasons and Endorsement". In C. Weiss(Ed.), Constructive Semantics, Springer. Cham. Springer, pp. 15-84.

Rahman, S. McConaughey, Z., Klev, A. \& Clerbout, N. . (2018).

Immanent Reasoning or Equality in Action, Dordrecht: Springer.

Recanati, F. (2002).

"Unarticulated constituents". Linguistics and Philosophy, vol. 25, pp. 299-345.

Recanati, F. (2004). Literal Meaning. Cambridge: CUP.

Recanati, F. (2007a).

Perspectival Thought. Oxford: OUP.

Recanati, F. (2007b).

“It's raining (somewhere)". Linguistics and Philosophy, vol. 30, pp. 123-146.

Recanati, F. (2010).

Truth Conditional Pragmatics. Oxford: OUP. Recanati, F. (2012).

Recanati; F. (2017).

“About the Lekton. Response to Kölbel”. In I. Depraetere \& R. Salkie (Eds.), Semantics and Pragmatics: Drawing a Line. Cham: Springer, 2017, pp. 215-224.

Sakai, T. (2014) 
[Review] “Truth-Conditional Pragmatics. By François Recanati. Oxford University Press, 2010, vii+324pp.”. English Linguistics (edited by the English Linguistic Society of Japan), vol. 31, pp. 365-375.

Soames, S. (2002)

Beyond Rigidity. Oxford. Oxford University Press.

Soames, S. (2005)

“Naming and Asserting”. In Z. Szabo (ed.), Semantics Versus Pragmatics . Oxford: Oxford University Press, pp. 356-82.

Stanley, J. (2005)

"Review of François Recanati’s Literal Meaning,” Notre-Dame Philosophical Reviews, online at http://ndpr.nd.edu/news/24857/?id=3841.

Sundholm, G. (1997).

"Implicit Epistemic Aspects of Constructive Logic". Journal of Logic, Language and Information, 6(2), pp. 191-212.

Sundholm, G. (2001).

“A Plea for Logical Atavism”. In O. Majer (Ed.), The Logica Yearbook 2000 (pp. 151-162). Prague: Filosofía. Taylor; K. (2001).

“Sex, Breakfast and Descriptus Interruptus”. Synthese, vol. 128, pp. 45-61. 